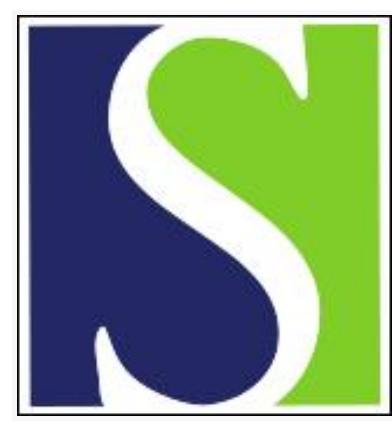

Scand J Work Environ Health 1988;14(6):390-397

https://doi.org/10.5271/sjweh.1904

Issue date: Dec 1988

Tobacco smoke removal with room air cleaners.

by Olander L, Johansson J, Johansson R

Affiliation: National Institute of Occupational Health, Solna, Sweden.

This article in PubMed: www.ncbi.nlm.nih.gov/pubmed/3212415 


\title{
Tobacco smoke removal with room air cleaners
}

\author{
by Lars Olander, Johan Johansson, Rolf Johansson ${ }^{1}$
}

\begin{abstract}
OLANDER L, JOHANSSON J, JOHANSSON R. Tobacco smoke removal with room air cleaners. Scand $J$ Work Environ Health 14 (1988) 390-397. The ability of room air cleaners to remove gases and particles from air contaminated with tobacco smoke has been studied. Thirty-one air cleaners were tested. Various air-cleaning devices were used, ie, electrostatic precipitators, electret fiber filters, ionizers, activated carbon, impregnated alumina, ionizing lamps, and an electron generator. The airflow rates were in the range of $0-500 \mathrm{~m}^{3} / \mathrm{h}$. The measurements covered particle sizes of $0.01-7.5 \mu \mathrm{m}$ and the following gases: carbon monoxide, ammonia, formaldehyde, nitric oxide, nitrogen dioxide, hydrocarbons, and hydrogen cyanide. No formal standard procedure exists for testing room air cleaners; therefore the tests were made in the following way. Tobacco smoke was generated and mixed in a closed room. The room air cleaner was started, and the decay rates for the gases and particles were measured. The results were calculated as equivalent airflow rates, ie, the clean airflow rate causing the same decay rate for contaminant concentrations in a room. The equivalent airflow rates were $0-360 \mathrm{~m}^{3} / \mathrm{h}$. The rate of ozone emission by electrostatic precipitators and ionizers was also measured. One general conclusion was that it is much more difficult to remove gases than particles.
\end{abstract}

Key terms: cleaning efficiency, equivalent airflow rate, gases, particles, sidestream smoke, test method.

Air cleaning is difficult to achieve effectively, both for particles and for gases, and the difficulties multiply when the intention is to clean particles and gases from air simultaneously. One common indoor air contaminant is environmental tobacco smoke, which consists of both particles and gases $(16,19)$ and is consequently very difficult to remove from the air.

There are many different techniques for purifying air of both particles and gases (2). Nearly all of these techniques have been used in one way or another in the room air cleaners available commercially for tobacco smoke. Most of these cleaners are not made especially for cleaning tobacco smoke from air, but they are for sale as such. The price is about USD 100-2000, and the installation is very easy. Therefore many people have been buying room air cleaners to rid their homes, offices, restaurants, and other places of the annoyance of tobacco smoke when it is hard or impossible to use other methods to diminish the problem.

Other methods of getting rid of tobacco smoke exist, and they have very different efficiencies. The most effective is to prohibit smoking. Smoking may also be permitted only in separate rooms, or the ventilation in rooms with smokers may be increased.

Increased ventilation is not always easy to arrange. In addition the intake air that ideally should be clean is often polluted by air contaminants from cars, industries, and heating systems, and thus sometimes it is necessary to use a cleaning system to get fresh air into the building. Even if the outside air is clean enough to be used without cleaning, an increased ven-

\footnotetext{
1 National Institute of Occupational Health, Solna, Sweden.
}

Reprint requests: to Mr L Olander, Ventilation Division, $\mathrm{Na}$ tional Institute of Occupational Health, S-171 84 Solna, Sweden. tilation airflow rate means increased costs. The greatest proportion of the cost of both installation and operation will be for the heating of the air, even if a heat recovery system is used.

These circumstances have made it very popular to use room air cleaners, ie, air cleaners small enough to be used in ordinary offices or living rooms, as an alternative for increased ventilation. The room air cleaners are often used for tobacco smoke but also for other air contaminants. However, there has been no summary of the efficiency of all the available air cleaners used to clean tobacco smoke from air. During the last few years there have been some reports on the efficiency of a few cleaners with respect to some of the contaminants in tobacco smoke $(7,17,18)$, usually the particles. The present report concerns measurements done on nearly all available room air cleaners intended for tobacco smoke. It shows their efficiency both for particles and for some of the gases in tobacco smoke.

\section{Materials and methods}

\section{The cleaners}

The intention was to include all the air cleaners available in Sweden for purifying the air of tobacco smoke. However, it was necessary to limit the cleaners to one example of each cleaning principle from each vendor or manufacturer. Therefore the size of the cleaners evaluated was limited according to the following criteria. Each air cleaner should be usable in a normal office for one to four persons. In such offices the normal ventilation flow rate of outside air should be around $200 \mathrm{~m}^{3} / \mathrm{h}$, according to Swedish building regulations. If the air cleaner is to have a noticeable effect on the contaminant concentration in the room, its air- 
flow rate should be equal to at least $400 \mathrm{~m}^{3} / \mathrm{h}$ because the flow rate of the clean air from a cleaner is the product of the flow through the cleaner and the cleaning efficiency. If a cleaner is any good, it ought to have a cleaning efficiency of at least $50 \%$. Therefore, in order to give a so-called equivalent airflow rate (cleaning efficiency $\times$ airflow rate) of $200 \mathrm{~m}^{3} / \mathrm{h}$, it should have an airflow rate of around $400 \mathrm{~m}^{3} / \mathrm{h}$.

An attempt was made to obtain a sample of all the room air cleaners found on the market with an airflow rate of around $400 \mathrm{~m}^{3} / \mathrm{h}$. Some of the cleaners were not equipped with a built-in fan, and for these we chose a size that, according to the salesman, was suitable for the mentioned room type. In all, 31 different types of cleaners were tested (12). These cleaners had many different combinations of cleaning systems for particles and gases. In fact most of the cleaners that were intended for tobacco smoke were only cleaning the particles from the air.

The cleaners were divided into five groups according to their main cleaning system for particles. The first group consisted of six cleaners with fiber filters and with measured airflow rates of $310-470 \mathrm{~m}^{3} / \mathrm{h}$. Two of the six contained activated carbon filters, and one had impregnated alumina (Purafii ${ }^{\circledR}$ ) for gas cleaning purposes. The second group consisted of six electret fiber filters $\left(110-400 \mathrm{~m}^{3} / \mathrm{h}\right)$. Of these one had an activated carbon filter, one had some impregnated alumina, and one had an ionizer which should clean gases from the air. The third group consisted of five electrostatic precipitators without gas cleaning equipment $\left(170-470 \mathrm{~m}^{3} / \mathrm{h}\right)$. The fourth group consisted of seven electrostatic precipitators equipped with gas cleaning equipment $\left(230-550 \mathrm{~m}^{3} / \mathrm{h}\right)$, ie, activated carbon in six and an ionizer in one. The fifth group consisted of seven ionizers divided into three subgroups. The first subgroup consisted of four ionizers, two of which had a fan $\left(60-100 \mathrm{~m}^{3} / \mathrm{h}\right)$ and one of the two had some impregnated alumina. The second subgroup contained two cleaners with some type of ionizing ultraviolet lamp, and of these one had a fan $\left(100 \mathrm{~m}^{3} / \mathrm{h}\right)$. The third subgroup consisted of one cleaner with an electron generator and a fan (probably for cooling purposes). These descriptions originated mostly from the manuals or the brochures released by the manufacturers. Only when it was not possible to get a manual was the description made from a visual inspection of the cleaner.

Generally the nominal airflow rates given by the manufacturer diverged from the measured values. The measured power consumption was $2-150 \mathrm{~W}$.

\section{The tobacco smoke}

Tobacco smoke is a varying and complex air contaminant. It consists of liquid and solid particles of different sizes and of inorganic and organic gases. More than 3800 compounds have been identified in tobacco smoke (4). The particles, which mostly con- sist of organic substances, can coagulate to build larger particles, but they can also evaporate to increase the concentration of some of the gases. The gases can react chemically with other gases and particles. They can also condense on particles to increase particle size. Available surfaces can act as catalysts for chemical reactions and as precipitating surfaces for particles and as condensing surfaces for gases. All of these possibilities make measurements very difficult.

Many measurements of tobacco smoke have been reported mostly of smoke from cigarettes under different conditions (4). There is a difference between the mainstream smoke and the sidestream smoke of cigarettes. Mainstream smoke is the smoke inhaled and, to some extent, exhaled by the smoker. Sidestream smoke spreads from the glowing part of the cigarette directly to the surrounding environment. It is mostly sidestream smoke that is an irritant to other people. Nearly always, the amount of generated contaminants is larger in sidestream smoke than in mainstream smoke. Sidestream smoke also contains more, and smaller, particles than mainstream smoke. Most of the smoke in a room is originally sidestream smoke diluted in room air, and an air cleaner should be able to capture the types of contaminants that exist in this type of smoke. If it does, it will also capture mainstream smoke with high efficiency.

Because of the difficulties of generating and measuring exhaled mainstream smoke, the test of the air cleaners was done only with sidestream smoke. The smoke was generated at two concentration levels because of the measurement systems. One concentration was obtained from smoke from 20 cigarettes in a closed room of $100 \mathrm{~m}^{3}(5 \mathrm{~m} \times 5 \mathrm{~m} \times 4 \mathrm{~m})$ and the other from smoke from one cigarette in the same room. The smoking was performed according to standard smoking conditions (9), which call for a $35-\mathrm{ml}$ puff during $2 \mathrm{~s}$ once in a minute for each cigarette. In this case each cigarette was consumed in eight puffs.

\section{Instrumentation}

The particle concentrations under both measurement conditions were measured with a Thermo-systems Inc (TSI) electrical aerosol analyzer 3030 (22) for particle diameters between 0.01 and $1 \mu \mathrm{m}$ in eight intervals (electromobility-equivalent diameters). The particle concentrations from one cigarette were also measured with a Particle Measuring Systems (PMS) LAS-X analyzer (19) for diameters between 0.1 and $7.5 \mu \mathrm{m}$ in 15 intervals (optical-equivalent diameters).

The following gases were measured with direct-reading instruments: carbon monoxide, hydrocarbons, ammonia, nitric oxide, nitrogen dioxide, hydrogen cyanide, and ozone. Formaldehyde was sampled at regular intervals in impinger flasks. Carbon monoxide was monitored with a Maihak Unor nondispersive infrared gas analyzer (21). The decreases in the concentration of the hydrocarbons (only relative) and ammonia were 
Table 1. The initial concentration of gases and particles in the sidestream smoke from 20 cigarettes in a closed room of $100 \mathrm{~m}^{3}$ and the total emission per cigarette. Background levels have been subtracted in the calculated yield per cigarette.

\begin{tabular}{lcc}
\hline Contaminant & $\begin{array}{c}\text { Initial } \\
\text { concentration }\end{array}$ & $\begin{array}{c}\text { Total emission } \\
\text { per cigarette }\end{array}$ \\
\hline Gases & & \\
$\quad$ Carbon monoxide & $12 \mathrm{ppm}$ & $59 \mathrm{mg}$ \\
Ammonia & $2 \mathrm{ppm}$ & $7.8 \mathrm{mg}$ \\
Formaldehyde & $0.4 \mathrm{ppm}$ & $2.4 \mathrm{mg}$ \\
Nitric oxide & $0.3 \mathrm{ppm}$ & $1.6 \mathrm{mg}$ \\
Nitrogen dioxide & $0.05 \mathrm{ppm}$ & $0.4 \mathrm{mg}$ \\
Hydrogen cyanide & $0.05 \mathrm{ppm}$ & $0.3 \mathrm{mg}$ \\
$\quad$ Hydrocarbons & $\cdot$ & $\cdot$ \\
Particles (>0.03 $\mu \mathrm{m})$ & & \\
$\quad$ Number & $3.8 \cdot 10^{11 / \mathrm{m}^{3}}$ & $1.9 \cdot 10^{12}$ \\
Volume & $2.4 \mathrm{~mm}^{3} / \mathrm{m}^{3}$ & $12 \mathrm{~mm}^{3}$ \\
\hline
\end{tabular}

$\left(\right.$ Particles $\left./ \mathrm{m}^{3}\right) / \log \left(\mathrm{D}_{\max } / \mathrm{D}_{\min }\right)$

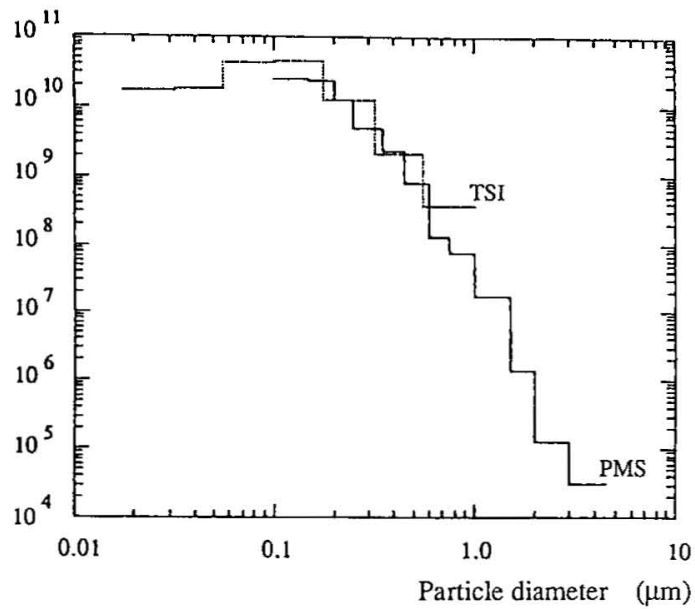

Figure 1. Number distribution of the particles in the sidestream smoke from one cigarette in a closed room of $100 \mathrm{~m}^{3}$. (TSI = Thermo-systems Inc, PMS = Particle Measuring Systems, $\mathrm{D}=$ diameter)

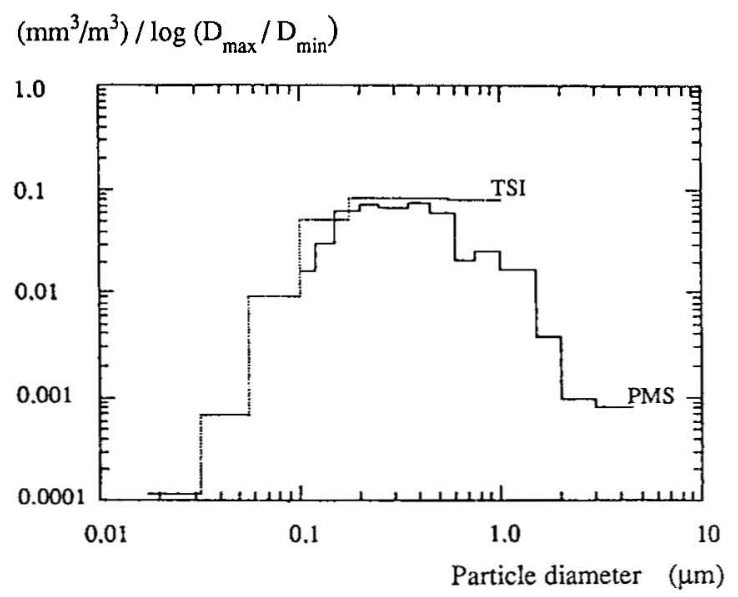

Figure 2. Volume distribution of the particles in the sidestream smoke from one cigarette in a closed room of $100 \mathrm{~m}^{3}$. (TSI = Thermo-systems Inc, PMS = Particle Measuring Systems, $D=$ diameter) measured with two Miran 1A infrared spectrophotometers at 3.4 and $10.8 \mu \mathrm{m}$, respectively (6). Nitric oxide and nitrogen dioxide were analyzed with a Monitor Labs $8440 \mathrm{E} \quad \mathrm{NO} / \mathrm{NO}_{\mathrm{x}} / \mathrm{NO}_{2}$ chemiluminescence analyzer (8). Hydrogen cyanide was monitored with a CEA TGM 555 continuous colorimetric analyzer (3). Formaldehyde was analyzed with a modified chromotropic acid method. In each formaldehyde test five samples were taken at regular intervals (1). The ozone emission rates from the electrostatic precipitators and the ionizers were measured with a Dasibi $1003 \mathrm{AH}$ ozone monitor and a Dasibi 1008 RS ozone monitor (5). The ozone concentrations were measured at the air outlets of the cleaners, and the background levels were subtracted. The ozone concentration at the crosssection of the air outlet was not uniform. It was therefore necessary to obtain an average of both the air velocity and ozone concentration at a number of points at the cross-section. The number of measuring points was, in each case, dependent on the size and shape of the air outlet.

\section{Measurements}

The air cleaners were tested according to their ability to remove particles and gases from the atmosphere in the closed room. All particles larger than $0.01 \mu \mathrm{m}$ and seven gases of different types were monitored. Due to the disparate sensitivity of the measuring instruments, each cleaner had to be tested with two different concentrations, that of smoke from 20 cigarettes and that of smoke from one cigarette. We assessed the efficiency of each cleaner by monitoring the rate of decay of the concentrations of the particles and the gases. The gases were monitored only in the tests with 20 cigarettes.

The test procedure was as follows. The air cleaner was placed in the center of the room. The room was sealed airtight, and 20 cigarettes (Red Prince) were smoked $(8.5 \mathrm{~min})$ by a smoking machine. Thereafter the smoke was thoroughly mixed for $4 \mathrm{~min}$, and then the initial gas concentrations were measured for $20 \mathrm{~min}$ before the cleaner was started. Thereafter the concentrations of the gases and particles were monitored for a period of $2 \mathrm{~h}$. Table 1 shows the initial concentration of the sidestream smoke from 20 cigarettes. After the measurements the room was purged with clean air, and a second test, for particle content only, was performed with the smoke from one cigarette. During both tests a mixing fan $\left(150 \mathrm{~m}^{3} / \mathrm{h}\right)$ was also on. Figures 1 and 2 show the number and volume distribution from the sidestream smoke of one cigarette. The figures show that most of the particles had a size below $0.3 \mu \mathrm{m}$, which means that they were respirable. They also show that most of the particle volume (and also the particle mass) was in the size interval between 0.1 and $0.8 \mu \mathrm{m}$. Therefore most of the particle fraction of the environmental tobacco smoke is both respirable and difficult to collect on filters. Since some of the cleaners could have a very high initial efficiency, 
the measurements were made only after each cleaner had been used once in a dummy measurement with the smoke from 20 cigarettes. After the measurements the equivalent airflow rate for each particle size and each gas was calculated with the following equation:

$$
\eta \cdot Q=\frac{V}{t_{1}-t_{0}} \cdot \ln \frac{C_{0}}{C_{1}}\left(m^{3} / h\right)
$$

equation 1

where $\eta \cdot Q=$ equivalent airflow rate $\left(\mathrm{m}^{3} / \mathrm{h}\right), \eta=$ filtration efficiency $(0-1), Q=$ airflow rate through the cleaner $\left(\mathrm{m}^{3} / \mathrm{h}\right), \mathrm{V}=$ volume of the room $\left(\mathrm{m}^{3}\right), \mathrm{C}_{\mathrm{O}}=$ initial concentration (at time $\left.\mathrm{t}_{0}\right)\left(\mathrm{mm}^{3} / \mathrm{m}^{3}\right)$, and $\mathrm{C}_{1}=$ concentration (at time $\left.\mathrm{t}_{1}\right)\left(\mathrm{mm}^{3} / \mathrm{m}^{3}\right)$.

This equation is accurate if the room is completely closed, the concentration is homogeneous, and the influence of the room is negligible (23). However, the influence of the room could not initially be assumed to be negligible, and therefore the same measurements (as with the cleaners) were made in the room without any cleaner.

The method used to measure the equivalent airflow rates makes it possible to compare the cleaners, even if they do not have any airflow rate at all, as for example some of the ionizers. It also makes it possible to compare the results with the influence of normal ventilation airflow rates.

In order to present the results of the particle measurements, we have made the following calculations. Assuming that the particles were spherical, we summarized the volume of all the particle sizes and calculated the total equivalent airflow rate for each cleaner for the two initial concentration levels measured with the TSI analyzer and for the low initial concentration measured with the PMS analyzer. The values for the two instruments were approximately the same at the low concentration level. The equivalent airflow rate for each particle size has been published in references $10,11,13,14$, and 15 . The performance of a cleaner varied with the concentration level, and, since the instruments measured different particle size intervals, all three values have been presented. The measured equivalent airflow rates generally decreased somewhat during extended operation times, and the values presented are for the first hour.

\section{Results}

The measured values for the equivalent airflow rates for the particles (total volume) in the initial concentration of smoke from one cigarette and smoke from twenty cigarettes are presented in figures $3-7$ for the five groups of room air cleaners. In figures $8-10$ the results for three of the gases and in figures $11-13$ the results for the other three gases are presented. For some of the electrostatic precipitators and ionizers, the nitrogen dioxide concentrations were increased (figures 8 and 10 ). No results are presented for carbon monox-

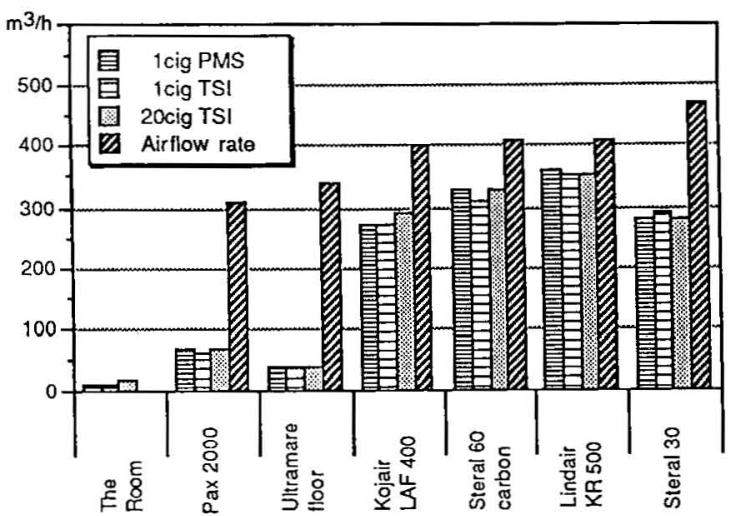

Figure 3. Equivalent airflow rates of the fiber filters with respect to the total volume of the particles in smoke from 1 and 20 cigarettes and the measured airflow rates. (PMS = Particle Measuring Systems, TSI = Thermo-systems Inc)

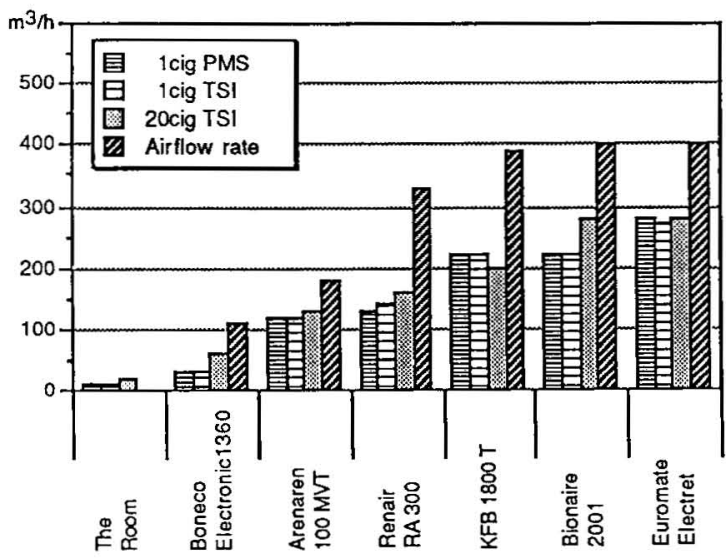

Figure 4. Equivalent airflow rates of the electret fiber filters with respect to the total volume of the particles in smoke from 1 and 20 cigarettes and the measured airflow rates. (PMS = Particle Measuring Systems, TSI = Thermo-systems Inc)

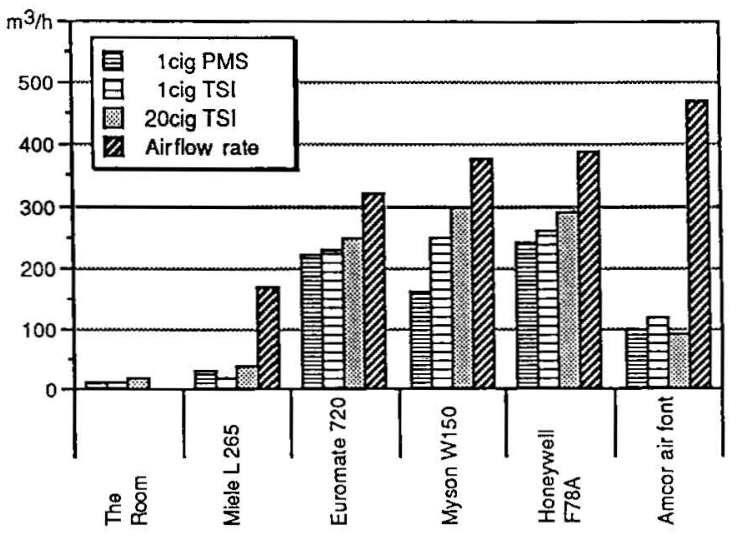

Figure 5. Equivalent airflow rates of the electrostatic precipitators without gas cleaning equipment with respect to the total volume of the particles in smoke from 1 and 20 cigarettes and the measured airflow rates. (PMS $=$ Particle Measuring Systems, TSI = Thermo-systems Inc) 


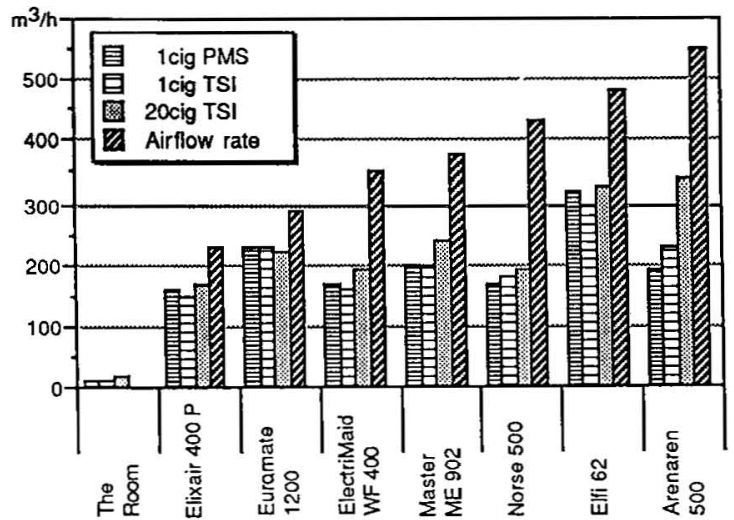

Figure 6. Equivalent airflow rates of the electrostatic precipitators with gas cleaning equipment with respect to the total volume of the particles in smoke from 1 and 20 cigarettes and the measured airflow rates. (PMS = Particle Measuring Systems, TSI = Thermo-systems Inc)

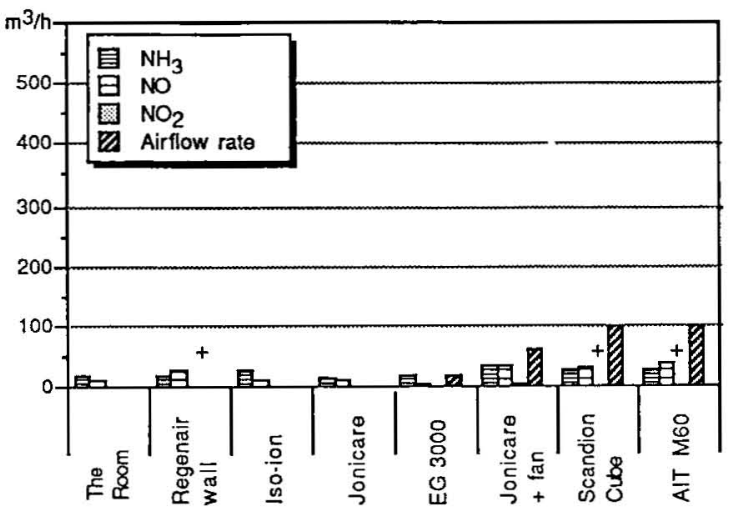

Figure 8. Equivalent airflow rates of the fiber filters and the electret fiber filters with respect to the gases ammonia $\left(\mathrm{NH}_{3}\right)$, nitric oxide (NO), and nitrogen dioxide $\left(\mathrm{NO}_{2}\right.$ ) and the measured airflow rates. A plus sign $(+)$ indicates that nitrogen dioxide was emitted.

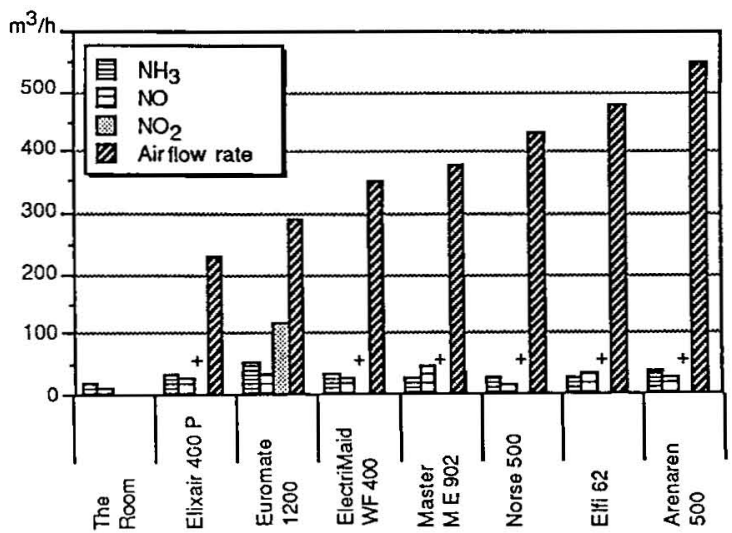

Figure 10. Equivalent airflow rates of the ionizers with respect to the gases ammonia $\left(\mathrm{NH}_{3}\right)$, nitric oxide (NO), and nitrogen dioxide $\left(\mathrm{NO}_{2}\right)$ and the measured airflow rates. A plus sign $(+)$ indicates that nitrogen dioxide was emitted.

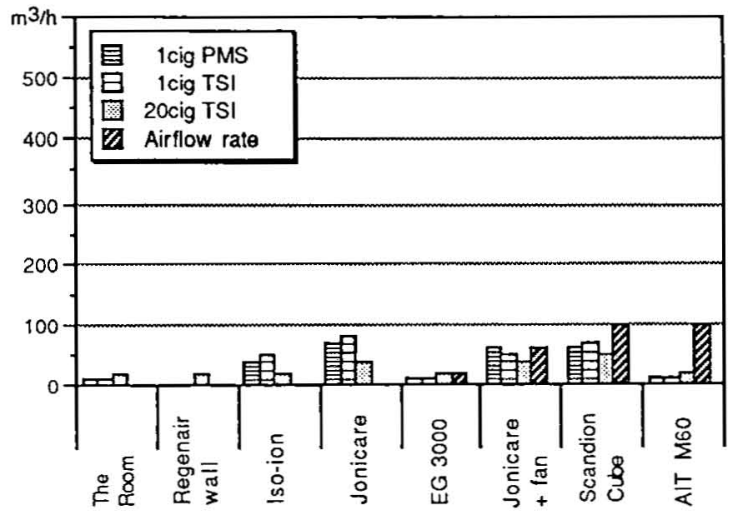

Figure 7. Equivalent airflow rates of the ionizers with respect to the total volume of the particles in the smoke from 1 and 20 cigarettes and measured airflow rates. (PMS = Particle Measuring Systems, TSI = Thermo-systems Inc)

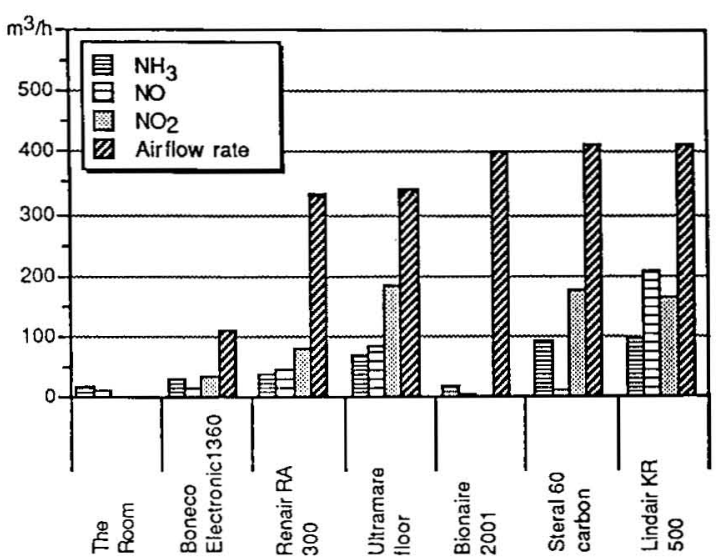

Figure 9. Equivalent airflow rates of the electrostatic precipitators with respect to the gases ammonia $\left(\mathrm{NH}_{3}\right)$, nitric oxide (NO), and nitrogen dioxide $\left(\mathrm{NO}_{2}\right)$ and the measured airflow rates.

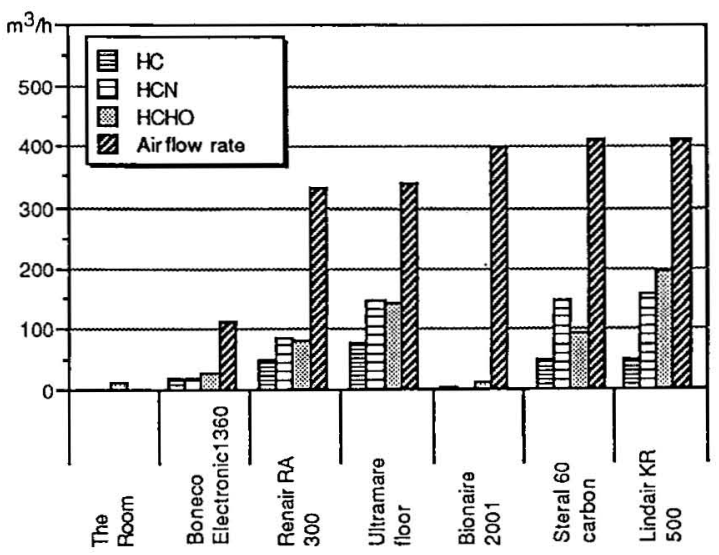

Figure 11. Equivalent airflow rates of the fiber filters and electret fiber filters with respect to the gases hydrocarbons $(\mathrm{HC})$, hydrogen cyanide $(\mathrm{HCN})$, and formaldehyde $(\mathrm{HCHO})$ and the measured airflow rates. 


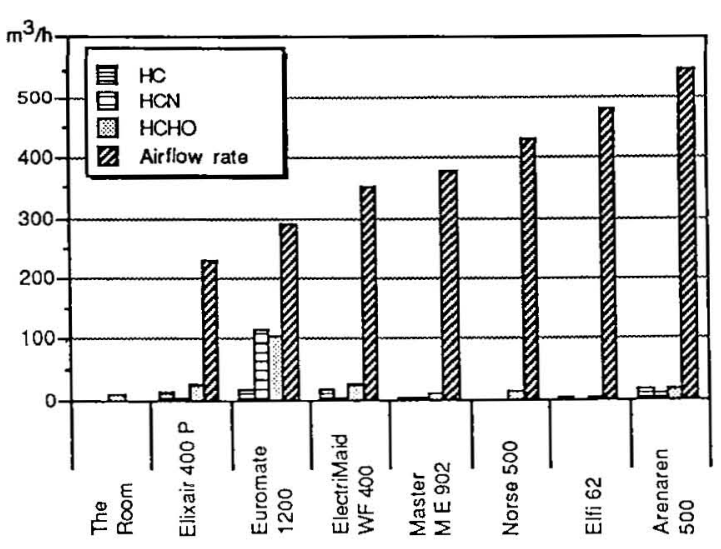

Figure 12. Equivalent airflow rates of the electrostatic precipitators with respect to the gases hydrocarbons $(\mathrm{HC})$, hydrogen cyanide $(\mathrm{HCN})$, and formaldehyde $(\mathrm{HCHO})$ and the measured airflow rates.

ide since none of the cleaners had any effect on this gas.

If a cleaner captures all incoming particles, or gases, the cleaning efficiency will be $100 \%$, and the equivalent airflow rate will be the same as the airflow rate through the cleaner. Therefore the measured airflow rates of the cleaners are also presented in figures $3-13$. The results from the measurements of the room without a cleaner are also presented in the figures. The measured values for the room are the aging of the smoke and also the attachment of the smoke to surfaces in the room $\left(130 \mathrm{~m}^{2}\right)$. It was not possible to substract the measured values for the room from the measured values for the cleaners. But the values for the room are generally so small in comparison with those of the cleaners that they do not matter. If the values of a cleaner are of the same size as those of the room, the effect of using that cleaner is minimal.

Ozone emission from electrostatic precipitators with gas-cleaning equipment was generally not detectable $(<1 \mathrm{mg}$ ozone $/ \mathrm{h}$ ), but in a few cases ozone concentrations of up to $6 \mathrm{mg} / \mathrm{h}$ were measured. Ionizers and electrostatic precipitators without gas-cleaning equipment also had low, but mostly detectable, ozone emission rates. The highest ozone emission rate measured was $33 \mathrm{mg} / \mathrm{h}$.

It is not possible to use these emission rates for calculating the ozone concentration levels in a room with an air cleaner, unless the influence of the room is considered. The decay rate of ozone in a room is rapid and depends on many factors. In reality the only way to have a low ozone concentration is to use a cleaner with a low emission rate.

\section{Discussion}

From figures $3-13$, it can be seen that some of the cleaners did, to some degree, clean the air of both gases

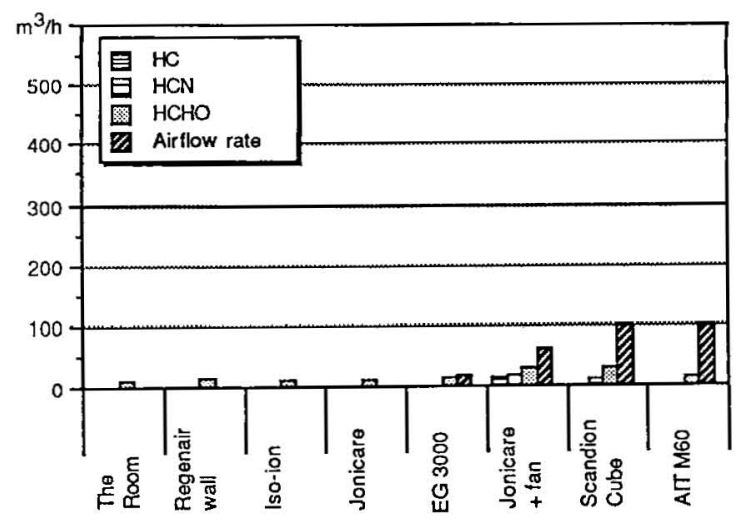

Figure 13. Equivalent airflow rates of the ionizers with respect to the gases hydrocarbons $(\mathrm{HC})$, hydrogen cyanide $(\mathrm{HCN})$, and formaldehyde $(\mathrm{HCHO})$ and the measured airflow rates.

and particles. For a cleaner with a gas filter it is necessary to change the filter at regular intervals.

To clean air of particles only, it is possible to choose between cleaners which demand washing regularly (eg, electrostatic precipitators) and those which demand regular changing of the particle filters. Air cleaners that are claimed not to need any maintenance (ionizers, ultraviolet lamps, electron generators) demand other types of maintenance, eg, washing of the walls and other surfaces.

Of the tested cleaners for particles, without gas filters, some had an equivalent airflow rate of around $200 \mathrm{~m}^{3} / \mathrm{h}$. They were the following: Euromate Electret, KFB 1800T, Honeywell F78A, Euromate 720, Myson W150, Kojair LAF-400, and Steral 30. Smaller flow rates were measured for Arenaren 100 MVT and Amcor Air Font, and even smaller rates were recorded for Miele L265 and Pax 2000. These cleaners, meant only for particle cleaning, diminished the particle concentrations considerably, but, at the same time, problems can occur with odors emanating from trapped compounds and from uncollected gases.

Most of the cleaners with a combination of particle and gas cleaning equipment did have an equivalent airflow rate for particles of at least $200 \mathrm{~m}^{3} / \mathrm{h}$. Those with the highest values for particles were Bionaire 2001, Arenaren 500, Elfi 62, Master ME 902, Euromate 1200 , Lindair KR 500, and Steral 60. For gases none of these combined cleaners reached an equivalent airflow rate of $200 \mathrm{~m}^{3} / \mathrm{h}$ for all of the seven measured gases. The cleaners with the highest values for the gases were Euromate 1200, Lindair KR 500, Utramare Floor, and Steral 60.

By means of an adequate activated carbon filter, it is possible to remove ozone generated from electrostatic precipitators and ionizers effectively. However, most of the activated carbon filters used in the air cleaners were thin and had a large air leakage. Nevertheless the ozone emission rates were very low 
for most of the cleaners. This low emission rate was probably due to adequately designed and maintained electrostatic precipitators and ionizers. Air cleaners which generated ozone also generated nitrogen dioxide if nitric oxide from the environmental tobacco smoke was present in the atmosphere.

When a room air cleaner is being chosen, one of the most important parameters must be the equivalent airflow rate, since it is this value that decides the effect of the cleaner in a room. However, there are many other parameters to take into consideration, such as airflow rate, weight, finish, size, need for maintenance, operating expenses, generated air movements in the room, noise level, and price. The present report concerns only the equivalent and actual airflow rates. In references $10,11,13,14$, and 15 weight, size, and power consumption have also been considered, along with a picture of each cleaner and the name of the vendor and the vendor's technical data on the cleaner.

This investigation has shown that there are some room air cleaners which rather effectively remove particles of environmental tobacco smoke from room air. Removal of the particulate phase does not however eliminate the odor and irritant effects of the tobacco smoke, many of which result from exposure to the gas phase contaminants produced.

There are also a few room air cleaners which, to some extent, also remove gases of the environmental tobacco smoke from room air. However none of the cleaners was able to diminish the concentration of carbon monoxide, which is generated in large amounts and is present in both mainstream and sidestream smoke.

Odors emanating from trapped tobacco smoke in the cleaners are a problem for most air cleaners, even if conventional gas-cleaning filters are used.

In conclusion, it is very difficult to clean the air of environmental tobacco smoke. The particle concentration can be reduced rather effectively, but the gaseous contaminants are much harder to collect. Therefore it is not possible to replace outside ventilation airflow rate with the airflow rate of room air cleaners. But, if a room air cleaner is used as a complement to outside ventilation airflow rate, it is possible to increase the air quality in a room with the condition that the cleaner operates well and is well serviced and well maintained.

\section{References}

1. Bachhausen P, Buchholz N, Hartkamp H. Bestimmung von Formaldehyd in Luft mit Hilfe von Chromotropsäure. 1. Mitteilung: Untersuchung zur Stabilität des Reagenses. Fresnius $Z$ Anal Chem 320 (1985) 347-349.

2. Calvert $S$. Partice control by scrubbing. In: Calvert $S$, Englund HM, ed: Handbook of air pollution technology. John Wiley \& Sons, New York, NY 1984, pp 135249.

3. CEA Instruments Inc. Operation manual for the TGM 555 air monitor. Emerson, NJ 1985.

4. Committee on Indoor Pollutants. Indoor pollutants. Na- tional Research Council, Washington, DC 1981.

5. Dasibi Environmental Corporation. Dasibi 1008 ozone analyser. Glendale, CA 1983.

6. Foxboro Company. MIRAN 1A general purpose gas analyzer: Operation, maintenance and service manual 001-4136. South Norwalk 1980.

7. Kimmel J. Performance of electrostatic precipitators in restaurants. In: Seifert B, Esdorn H, Fischer M, Rüden H, Wegner J, ed. Indoor air '87: Proceedings of the 4th international conference on indoor air quality and climate, Berlin (West), August 17-21, 1987. (Volume 3). Institute for Water, Soil and Air Hygiene, Berlin 1987, pp 226-230.

8. Monitor Labs Inc. Instruction manual for monitor labs nitrogen oxides analyser model 8440E. August 1977.

9. International Organization for Standardization. Cigarettes - Routine analytical cigarette-smoking machine - Definitions and standard conditions. Geneva 1986. (ISO 3308:1986).

10. Olander L, Johansson J. Mätningar av luftrenares effekt pả tobaksrök. Del II: Elekretfiberfilter [Performance of room air cleaners on tobacco smoke: Part II Electret fiber filters]. Arbetsmiljöinstitutet, Solna 1987. (Undersökningsrapport 1987: 16).

11. Olander L, Johansson $\mathbf{J}$. Mätningar av luftrenares effekt på tobaksrök. Del III: Elektrostatfilter utan gasrening [Performance of room air cleaners on tobacco smoke: Part III Electrostatic filters without gas cleaning]. Arbetsmiljöinstitutet, Solna 1987. (Undersökningsrapport 1987: 17).

12. Olander L, Johansson J, Johansson R. Luftrenares effekt på tobaksrök [The effect of room air cleaners on tobacco smoke]. Arbetarskyddsverket, Solna 1987. (Arbete och hälsa 1987: 28).

13. Olander L, Johansson J, Johansson R. Mätningar av luftrenares effekt på tobaksrök. Del I: Fiberfilter [Performance of room air cleaners on tobacco smoke: Part I Fiber filters]. Arbetsmiljöinstitutet, Solna 1987. (Undersökningsrapport 1987: 15).

14. Olander L, Johansson J, Johansson R. Mätningar av luftrenares effekt på tobaksrök. Del IV: Elektrostatfilter kombinerade med aktivt kol filter eller jonisator [Performance of room air cleaners on tobacco smoke: Part IV Electrostatic filters with activated carbon or ionizer]. Arbetsmiljöinstitutet, Solna 1987. (Undersökningsrapport 1987: 18).

15. Olander L, Johansson J, Johansson R. Mätningar av luftrenares effekt på tobaksrök. Del V: Jonisatorer [Performance of room air cleaners on tobacco smoke: Part V Ionizers, UV-radiaters and electron generator]. Arbetsmiljöinstitutet, Solna 1987. (Undersökningsrapport 1987: 19).

16. Repace JL, Lowrey $\mathrm{AH}$. Indoor air pollution, tobacco smoke, and public health. Science 208 (1980) 464-472.

17. Sandhagen R. Luftrenares effektivitet med avseende på tobaksrök. Examensarbete skyddsingenjörskursen [Efficiency of air cleaners on tobacco smoke: Work during Safety Engineer Course]. Arbetarskyddstyrelsen, Solna 1984.

18. Sextro RG, Offermann FJ, Nazaroff WW, Nero AV, Revzan K, Yater J. Evaluation of indoor aerosol control devices and their effects of radon progeny concentrations. In: Berglund B, Lindvall T, Sundell J, ed. I Indoor air. Volume 5. Byggforskningsrådet, Stockholm 1984, 235-239.

19. Sterling TD, Dimich H, Kobayashi D. Indoor byproduct levels of tobacco smoke: A critical review of the literature. J Air Pollut Control Assoc 32 (1982) 250-259.

20. Szymanski WW, Liu BYH. On the sizing accuracy of laser optical particle counters. Part Charact 3 (1986) $1-7$.

21. Verdin A. Gas analysis instrumentation. The MacMillan Press, London 1973. 
22. Whitby KT. Electrical measurements of aerosols. In: Liu BYH, ed. I Fine particles-aerosol generation, measurement, sampling, and analysis. Academic Press, New York, NY 1976, pp 581-624.

23. Whitby KT, Anderson GR, Rubow KL. Dynamic meth- od for evaluating room-size air purifiers. ASHRAE trans 89 (1983): part 2A; no 2771, 172-185.

Received for publication: 10 June 1988 